\title{
REVIEW
}

\section{A review about the impact of multiple sclerosis on health-related quality of life}

\author{
JULIÁN BENITO-LEÓN†*, JOSÉ MANUEL MORALES $\ddagger$, \\ JESÚS RIVERA-NAVARRO§ and ALEX J. MITCHELLף
}

\author{
$\dagger$ Department of Neurology, Móstoles General Hospital, Móstoles, Madrid, Spain \\ $\$$ Department of Research, Ministry of Labour and Social Affairs, Madrid, Spain \\ $\S$ Social Work Faculty, Veracruzana University, Veracruz, Mexico \\ - Academic Unit of Psychiatry, University of Leeds, Leeds, UK
}

Accepted for publication: July 2003

\begin{abstract}
Purpose: There is increasing recognition that the global wellbeing of patients with chronic neurological disease is an important outcome in research and clinical practice alike. Many studies involving individuals with multiple sclerosis have demonstrated that the overall wellbeing is not a simple manifestation of impairment or disability. The strongest correlations with health-related quality of life appear to be patient rated emotional adjustment to illness and patient rated handicap. In recent years, health-related quality of life questionnaires that measure the physical, social, emotional, and occupational impact of illness have been developed and validated in populations with MS. Most questionnaires are now available in a range of languages. This development is likely to lead to increasing recognition of neuropsychiatric complications of MS in clinical practice and better quantification of treatment responses in clinical trials.

Conclusion: Further work is required to decide which scale is most suited to which purpose. Assessment of multiple sclerosis-specific health-related quality of life should be included in future clinical trials to provide a complete picture of patients' health status.
\end{abstract}

\section{Introduction}

Multiple sclerosis (MS) is a chronic neurological disease characterized by macroscopic and microscopic areas of demyelination, linked with a broad spectrum of physical and social impairments. The combination of a progressive and unpredictable disease process creates an uncommonly stressful illness which power-

\footnotetext{
* Author for correspondence: Avda. de la Constitución 73, portal 3, $7^{\circ}$ Izquierda, E-28820 Coslada, Madrid, Spain; e-mail: jbenitol@meditex.es
}

fully impacts upon the quality of life (QoL) of both the patients and their relatives. ${ }^{1-3}$

QoL is not a new concept and early reference can be found in Greek literature. In its widest sense it embraces all aspects of well being and includes social, emotional, economic and cultural facets of our lives. Health Related QoL (HRQoL), as distinct from general QoL, is conceptualized as those aspects of life quality or function which are influenced by health status. This is broadly compatible with the World Health Organisation definition of health, namely that health is 'a state of complete physical, mental and social well-being and not merely the absence of disease or infirmity'. However, the term HRQoL is more specific and is based on health dimensions which can be measured. This ability to measure HRQoL in individuals over time brings important benefits. Quantifying HRQoL in different populations can identify subgroups with poor physical or mental health and can assist with interventions that may improve their health. Assessment of HRQoL is increasingly important for clinical research, clinical practice, and the decisionmaking process in health policy. ${ }^{4-7}$

The interest in HRQoL in MS is very recent. For many years research on the impact of MS was limited to an examination of the concepts of impairment and disability. ${ }^{8}$ The first paper that analysed the HRQoL in MS patients was published in 1992. In this landmark study, HRQoL was measured in 68 patients with MS, 164 patients with inflammatory bowel disease, and 75 patients with rheumatoid arthritis. ${ }^{9}$ HRQoL was lowest in the MS group. Over the last decade the literature on HRQoL in MS has grown exponentially. This has encompassed a growth of descriptive studies about the physical, emotional and social consequences of MS; the development of MS specific HRQoL instruments; 
and most recently an examination of the effects of disease-modifying therapies on HRQoL in MS patients. ${ }^{10}$ The purpose of this article is to review this literature concerning the impact of MS on HRQoL.

\section{Method}

We conducted a literature review using the principles of evidence based medicine. ${ }^{11}$ We used the text search terms (multiple sclerosis or MS) and (quality of life or QoL or handicap or function or participation) to identify all relevant English papers between 1966 and April 2003. We searched the electronic databases Medline, Embase, Web of Science and PsychInfo. We also contacted experts in the field and hand-searched a number of neurological journals. We excluded studies that did not discuss QoL and articles without primary data (review articles). The search identified approximately 330 published papers covering the major studies on this topic, of which 89 had enough suitable information to be discussed in this review.

THE INFLUENCE OF MULTIPLE SCLEROSIS ON HEALTHRELATED QUALITY OF LIFE

MS is a condition that has great potential to negatively affect HRQoL. Yet, it is important to acknowledge the wide range of individual differences in emotional and psychological adjustment to disease, even after the most disabling of impairments. ${ }^{12}$ People with MS report a lower life satisfaction than people without illness. ${ }^{13}$ They also report a lower satisfaction with life than people with several chronic illnesses including inflammatory bowel disease and rheumatoid arthritis as well as epilepsy and diabetes. ${ }^{9-14}$ Several features of MS may uniquely contribute to low HRQoL. ${ }^{10,15-19}$ Firstly, MS affects the integrity of normal physiological functioning in a diverse number of areas including neurological function (motor and sensory disturbances, sphincter problems and sexual dysfunction), neuropsychiatric function (cognitive impairment, mood disorder and psychosis), and other areas (for example, mobility and fatigue). Secondly, the disease is diagnosed primarily in young adults, which maximally influences productivity and personal development. Thirdly, MS has an unpredictable course, in which relapses and future disability are difficult for sufferers to anticipate. This makes it difficult for patients to maintain a sense of control over their disease. Fourthly, there is currently limited evidence for disease-modifying treatment and no possibility of cure. Finally, there are problems accessing the latest treatment due to inequalities in health care provision and there is a risk of drug-induced adverse effects. Thus it is imperative to be aware of the wider needs of patients. Yet, paradoxically, the effect of MS on HRQoL has often been widely overlooked in routine clinical practice and in most clinical trials. Instead, physicians have concentrated on the assessment of physical disability in MS, perhaps best exemplified by the Expanded Disability Status Scale of Kurtzke (EDSS)..$^{20}$ Although the EDSS was a major breakthrough it is now recognized to have psychometric limitations, including relatively poor responsiveness, and a narrow focus. ${ }^{21}$ Subsequently other scales have been devised, such as the Multiple Sclerosis Functional Composite. ${ }^{22}$ This is a multidimensional clinical outcome measure that includes quantitative tests of leg function/ambulation (Timed 25-Foot Walk), arm function (9-Hole Peg Test), and cognitive function (Paced Auditory Serial Addition Test). However, disability and handicap scales such as the EDSS and the Functional Composite have other limitations. They rely on assessment by neurologists rather than patients and they also omit domains of health that contribute to overall QoL. These are important points as clinicians and patients do not agree on what aspects of the disease are most important. ${ }^{23}$ Research shows that clinicians are most concerned about the physical manifestations of disease, whereas patients tend to identify role limitations, cognition and emotional problems as the most significant influences upon wellbeing. ${ }^{23,24}$ A further aspect overlooked by conventional scales is the huge burden on families and informal caregivers. This burden is under-studied and under-reported but is comparable to the burden experienced by relatives of neurodegenerative disease. ${ }^{23}$ There is probably a relationship between carer and patient distress. ${ }^{25,26}$ This suggests that the opinion of MS patients and caregivers should be considered in clinical trials and that outcomes should be widened to include domains which affect patient distress and family stress, a philosophy incorporated within the concept of HRQoL. ${ }^{27}$ As a complement to the assessment of physical disability, physicians must also recognise the need for instruments to evaluate general health, emotional and social functioning. This appreciation has resulted in the development of a series of new instruments to assess HRQoL some of which are generic and some of which are specific to MS. ${ }^{28}$

\section{GENERIC HRQOL INSTRUMENTS}

Generic measures of HRQoL are measures that were developed without a specific disease in mind and are therefore applicable to a wide range of populations. 
The main advantage of generic HRQoL instruments is their broad coverage and the fact that they allow comparisons of different populations across studies. A significant disadvantage is that they may not address topics of particular relevance to MS patients such as cognitive complaints. A consequence of their relatively poor coverage of specific symptoms in MS is that they are less responsive to treatment-induced changes than MS-specific measures. Nevertheless, studies involving generic HRQoL instruments have provided important data. These include:

(1) The initial identification of broad areas impacted by MS that had not previously been considered by conventional clinical scales. ${ }^{10,16,18,19,28-32}$

(2) The demonstration that the HRQoL in patients with MS is, on average lower than HRQoL in control subjects or in patients with other diseases. ${ }^{9}, 13,14,33,34$

(3) Assessment of MS HRQoL in clinical trials. ${ }^{35-40}$

Table 1 shows a selection of the generic HRQoL instruments that have been used in MS studies to date. The most widely used generic instrument is the SF-36, which is generally considered to be the gold standard generic measure of health status and has been validated cross-culturally in MS.44,46-52 The SF-36 is a broad measure of disease impact rated by sufferers themselves. In MS all eight dimensions of QoL in the SF-36 are reduced compared with the general population. ${ }^{29}$ However, longitudinal studies have highlighted several limitations of the SF-36, including a relatively poor responsiveness and contamination from changes in physical disability. ${ }^{53}$ Moreover, when using the SF-36 in MS patients, summary scores should be reported with caution. ${ }^{54}$ On the other hand, the SF-36 mental health summary scales appear to overestimate mental health in MS sufferers, despite a high prevalence of emotional and cognitive disorders. ${ }^{55}$

\section{TYPES OF MS-SPECIFIC HRQOL INSTRUMENTS}

New MS-specific measures of HRQoL have been developed in an attempt to reduce the weaknesses inherent in the generic instruments (table 2). Once developed, further work is required to translate them into different languages, or explore their validity in different settings.

\section{Multiple Sclerosis Quality of Life 54}

The MSQOL-54 was the first MS-specific HRQoL instrument. ${ }^{56-59}$ It consists of a generic instrument

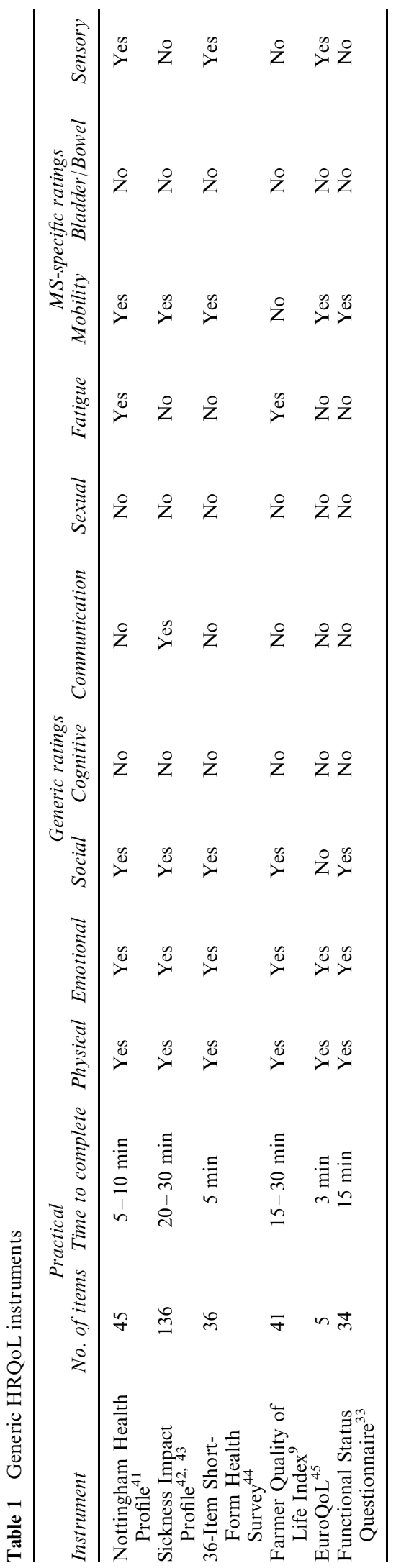




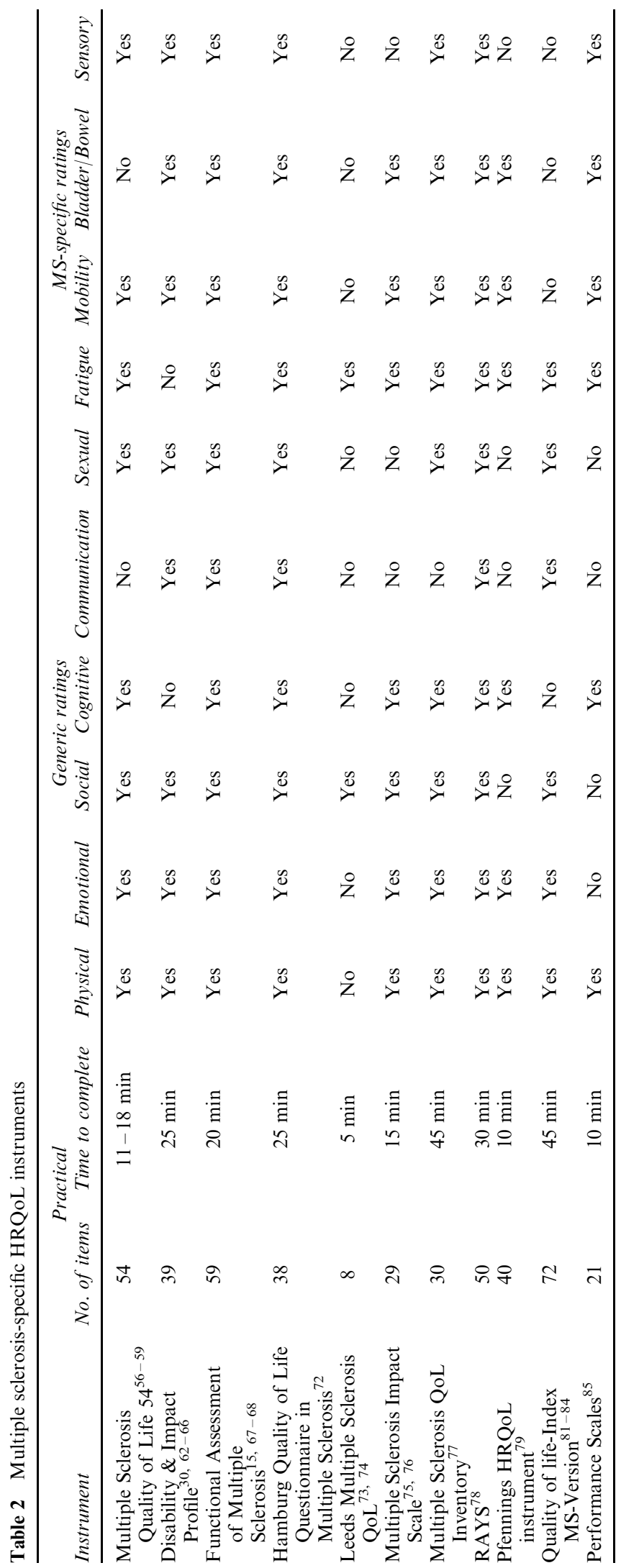

(RAND 36-Item Health 1.0$)^{60}$ as a core measure, supplemented with 18 additional items in the areas of health distress (four items), sexual function (four items), satisfaction with sexual function (one item), overall quality of life (two items), cognitive function (four items), energy (one item), pain (one item), and social function (one item). The generic component enables a comparison of HRQoL in MS patients to those of other patient populations and to the general population. The final MSQOL-54 instrument, contains 52 items distributed into 12 subscales along with two summary scores, and two additional single-item measures. The subscales are: physical function, role limitations - physical, role limitations-emotional, pain, emotional well-being, energy, health perceptions, social function, cognitive function, health distress, overall quality of life, and sexual function. The summary scores are the physical health composite summary and the mental health composite summary. The single item measures are satisfaction with sexual function and change in health. This instrument, which was validated in one study including 183 MS patients, has a good internal consistency and test-retest reliability, ${ }^{56}$ but its validity and sensitivity to change has been criticised. ${ }^{61}$

\section{Disability and Impact profile}

The Disability \& Impact profile $(D I P)$ has been used in several studies. ${ }^{30,62-66}$ This instrument, which was validated in a sample of 73 MS patients, contains three symptoms questions (pain, visible deformities and worry about deterioration), as well as 36 questions in five areas: mobility, self-care, communication, social activities and psychological status. The results are presented in a profile of weighted scores that take into consideration the '(dis)ability' and 'impact' aspects. By means of this profile and by means of so-called major disruptions of HRQoL, which are defined as a loss on weighted score on more than $50 \%$, the DIP provides indications for treatment and care. Internal consistency and test reliability are high for all scales of the DIP..$^{30,62-66}$

\section{Functional Assessment of Multiple Sclerosis}

The original version of the Functional Assessment of Multiple Sclerosis (FAMS) instrument, which was validated in one sample of 433 MS patients, comprises 59 items capturing six main QoL domains: Mobility (7 items), Symptoms (7 items), Emotional Well-being (7 items), General Contentment (7 items), Thinking/Fatigue (9 items) and Family/Social Well-being ( 7 items). 
All six FAMS subscales (44 items total) demonstrated very good reliability. Areas of concern to MS patients that do not fall in these six general domains are included in the Additional Concerns subscale (15 items). ${ }^{15,67,68} \mathrm{An}$ analysis of this FAMS version, applied in a sample of 308 Spanish MS patients, showed high internal consistency reliability if eight additional MS-specific items, which had been initially excluded from the original version, were included. ${ }^{69}$ The main limitation of the original FAMS is that it is unduly weighted toward psychosocial consequences of disease. In contrast, the Spanish modified version of the FAMS instrument includes additional items about MS symptoms, which increases its validity and range of coverage. ${ }^{69,70}$ In a recent study, FAMS instrument has been recommended for measuring QoL in MS patients instead of the MSQoL-54, since this latter instrument suffers from floor effects on physical health subscales. ${ }^{71}$ The original version of the FAMS is a very useful disease-targeted instrument to evaluate MS patients' HRQoL. ${ }^{15,67,68}$ However, we feel that the modified FAMS offers a more holistic assessment of neurological symptoms and psychosocial complaints associated with MS in line with published recommendations regarding specific HRQoL instruments. ${ }^{57,71}$

\section{Hamburg Quality of Life Questionnaire in Multiple Sclerosis}

The Hamburg Quality of Life Questionnaire in Multiple Sclerosis (HAQUAMS, in German) comprises 38 items. This instrument was validated in one study that included 237 MS patients. Validity was supported by correlation with FAMS. Reliability was high and satisfied psychometric standards. No floor or ceiling effects have been found in either of the HAQUAMS subscales. However, there is, as yet, no data about sensitivity to change. Of note, the HAQUAMS discriminated between MS patients with and without cognitive impairment. ${ }^{72}$

\section{Leeds Multiple Sclerosis Quality of Life}

The Leeds Multiple Sclerosis Quality of Life (LMSQoL) is a new eight-item instrument with a good internal consistency and test-retest reliability. Moreover, there are minimal floor or ceiling effects for the scale. The instrument is also easy to use and practical to administer in clinic or as a postal questionnaire. It also measures a construct related to well-being, and thus provides an useful adjunct to the measurement of outcome in MS. ${ }^{73,74}$

\section{Multiple Sclerosis Impact Scale}

The Multiple Sclerosis Impact Scale (MSIS-29) consists of 29 items that measure the physical (20 variables) and psychological (nine variables) impact of MS. The instrument, which was validated in 766 MS patients, has shown good validity, small floor and ceiling effects, high internal consistency, high test re-test reliability and preliminary evidence of good responsiveness. ${ }^{76}$ These results suggest that this instrument is a clinically useful and scientifically robust patient-based outcome measure. A recent study has demonstrated that the psychometric properties of the MSIS-29 are consistent across hospital based samples, and similar to those in the community samples. ${ }^{76}$

\section{Multiple Sclerosis Quality of Life Inventory}

The Multiple Sclerosis Quality of Life Inventory (MSQLI) is a modular MS-specific HRQoL instrument consisting of the Health Status Questionnaire (SF-36), supplemented by nine symptom-specific measures (covering fatigue, pain, bladder function, bowel function, emotional status, perceived cognitive function, visual function, sexual satisfaction, and social relationships). The MSQLI was validated in one study that included 300 MS patients. The level of validation was extensive, showing that the internal consistency of the total MSQLI and the subscales was good, with one exception (social relationships), and that the instrument has good construct validity. One advantage to using the MSQLI is that psychometrically sound short scales are available. Furthermore, when compared to the FAMS and the MSQoL-54, the MSQLI was most flexible since its components are separable. ${ }^{77}$

\section{$R A Y S$}

The RAYS scale has three subscales that cover different dimensions of HRQoL (physical, psychological, and social-familial) and each includes 15 self-report items scored from one (best) to four (worse). Validation was achieved through administration of the scale to 50 randomly selected MS patients and to 50 age, sex-, education- and family status-matched healthy controls. The instrument demonstrated high internal consistency and significant discriminative value. The RAYS subscales correlated significantly with the SF-36 scales, and the physical RAYS scale was moderately correlated with EDSS. ${ }^{78}$ 


\section{Pfennings HRQoL Instrument}

Pfennings et al. ${ }^{79}$ administered the SF-36; COOP/ WONCA Charts - the COOP Charts evaluate overall patient functioning through the use of pictorial representations of functioning levels; ${ }^{80}$ and DIP to $162 \mathrm{MS}$ patients. Factor analyses identified two underlying dimensions of HRQoL, relating to 'physical functioning' and 'psychological functioning'. Selection of the three highest loading reliable scales on each factor resulted in a final questionnaire consisting of three scales of the SF-36 and three scales of the DIP. In total 40 items were selected, requiring about $10 \mathrm{~min}$ to complete. This instrument is brief and adequately measures two dimensions of HRQoL. ${ }^{79}$

\section{Quality of Life-Index MS-Version}

The Quality of life-Index (QLI) was developed by Ferrans \& Powers to measure quality of life in terms of satisfaction with life. ${ }^{81}$ The QLI measures both satisfaction and importance regarding various aspects of life. QLI produces five scores: quality of life overall and in four domains (health and functioning, psychological/ spiritual domain, social and economic domain, and family). A number of versions of the QLI have been developed for use with various disorders, including MS. The QLI MS-version consists of 72 items covering physical symptoms, emotional and social sphere, sexual problems, and fatigue. ${ }^{82-84}$

\section{Performance Scales}

The Performance Scales are 7-level categorical rating scales with subscales for mobility, hand function, vision, fatigue, cognitive, bladder/bowel, sensory and spasticity symptoms. The total number of items is 21 . Impact on work productivity is assessed with separate items. This instrument has documented test-retest reliability and internal consistency reliability. However, it may be subject to recall bias as patient is asked to compare level of disability to function prior to disease. ${ }^{85}$

\section{HRQOL ASSESSMENT AS END-POINTS IN MS CLINICAL TRIALS}

Rapid development of potentially disease-modifying treatments has led to multiple drug trials in patients with both relapsing-remitting and secondary progressive MS. Unfortunately, not all groups have recognized the need to measure the possible benefits of treatment upon broadly defined patient and caregiver well-being. In the last few years, HRQoL assessments have gradually been incorporated into randomized controlled trials to evaluate the effectiveness of MS therapies, such as interferon. Although the use of HRQoL scales provides additional information that is important for treatment decisions and resource allocation, only a handful of Trialists have employed these measures as primary or secondary end-point in MS studies (table 3).

\section{HRQoL findings in randomized clinical trials of new drug treatments for $M S$}

Despite the advent of several MS-specific HRQoL instruments, all except one of the studies of interferon $\beta$ in relapsing-remitting MS patients have used a generic instrument. Results vary, ranging from no effect on HRQoL to definite improvement in physical dimensions. The reasons for the discrepancy in results is almost certainly related to methodological variations in the samples and their follow-up compounded by the use of different HRQoL instruments. Two studies have evaluated the effect of interferon $\beta$ on secondary progressive MS patients' HRQoL. In both studies, several HRQoL dimensions improved. ${ }^{39}$, 96 There is one study that has evaluated the HRQoL of MS patients who had suffered a relapse treated with intravenous methylprednisolone. There was statistically significant early improvement of EDSS and the Incapacity Status Scale scores and a trend towards improvement in the SF-36 physical and mental composites short of statistical significance. These results suggest that improvement of impairments and disability after treatment with intravenous methylprednisolone for a relapse of MS occurs early, while improvement of subjective health status is delayed..$^{32}$

HRQoL findings in randomized clinical trials of nonpharmacological trials in $M S$

Exercise training as well as physical rehabilitation, and T'ai chi programme are known to improve MS patients' HRQoL (see table 3). Therefore, this data supports the suggestion that patients should be encouraged to engage in regular daily exercise and patients who have significant disability should be offered rehabilitation programmes.

RELATIONSHIP BETWEEN CLINICAL VARIABLES AND HRQOL IN MS

The relationship between clinical variables and HRQoL in MS should be of considerable interest to clinicians since a knowledge of this relationship may 
Impact of MS on health-related quality of life

Table 3 Therapeutic interventions on MS in which a HRQoL instrument has been used

\begin{tabular}{|c|c|c|c|c|c|c|}
\hline & Therapy & MS type & Patients & Duration & Instrument & Results \\
\hline Petajan et al. ${ }^{86}$ & Aerobic training & $\mathrm{RR}$ & 54 & 15 weeks & SIP & All domains improved \\
\hline Jønsson et al. $^{87}$ & Rehabilitation programme & $\mathrm{PP} / \mathrm{SP}$ & 43 & NS & LLQ & All domains improved \\
\hline Di Fabio et al. $^{88}$ & $\begin{array}{l}\text { Outpatient Rehabilitation } \\
\text { programme }\end{array}$ & $\mathrm{PP} / \mathrm{SP}$ & 31 & 12 months & SF-36 & $\begin{array}{l}\text { The treatment group showed } \\
\text { improvements in six } \\
\text { dimensions that were not } \\
\text { improved in the wait-listed } \\
\text { group }\end{array}$ \\
\hline Schwartz et al. ${ }^{35}$ & Interferon $\beta 1 \mathrm{~b}$ & $\mathrm{RR}$ & 79 & 12 months & Q-TWIST & $\begin{array}{l}\text { No effect on the number of } \\
\text { months of quality-adjusted } \\
\text { time }\end{array}$ \\
\hline Sitzia et al. ${ }^{89}$ & Rehabilitation programme & $\mathrm{PP} / \mathrm{SP}$ & 33 & $5-10$ days & NHP & $\begin{array}{l}\text { Overall post-treatment } \\
\text { NHP-1 scores were } \\
\text { significantly better than } \\
\text { overall pretreatment scores } \\
\text { for MS patients }\end{array}$ \\
\hline Gianino et al. ${ }^{90}$ & $\begin{array}{l}\text { Intrathecal baclofen for } \\
\text { spasticity }\end{array}$ & SP & 15 & 12 months & SF-36 & $\begin{array}{l}\text { No effect on QLI scores, but } \\
\text { the SIP revealed significant } \\
\text { changes in the total score as } \\
\text { well as the physical and } \\
\text { psychosocial subscales. }\end{array}$ \\
\hline Nortvedt et al. ${ }^{36}$ & INF $\alpha 2-\mathrm{a}$ & $\mathrm{RR}$ & 97 & 12 months & QLI, SIP & $\begin{array}{l}\text { The adverse events } \\
\text { negatively affected the } \\
\text { patients'HRQoL }\end{array}$ \\
\hline Husted et al..$^{91}$ & T'ai chi programme & $\mathrm{PP} / \mathrm{SP}$ & 19 & 8 months & SF-36 & $\begin{array}{l}\text { Patients experienced } \\
\text { improvements in vitality, } \\
\text { social functioning, mental } \\
\text { health, and ability to carry } \\
\text { out physical and emotional } \\
\text { roles. }\end{array}$ \\
\hline Solari et al..$^{92}$ & Inpatient rehabilitation & $\mathrm{RR}$ & 50 & 15 weeks & SF-36 & $\begin{array}{l}\text { Mental domain improved at } \\
3 \text { and } 9 \text { weeks }\end{array}$ \\
\hline Freeman et al. ${ }^{93}$ & Inpatient rehabilitation & $\mathrm{PP} / \mathrm{SP}$ & 50 & 12 months & SF-36 & $\begin{array}{l}\text { The effect of inpatient } \\
\text { rehabilitation on disability } \\
\text { and HRQoL declined after } \\
\text { discharge }\end{array}$ \\
\hline Rice et al. ${ }^{37}$ & Interferon $\beta 1 \mathrm{~b}$ & $\mathrm{RR}$ & 117 & 60 months & SF-36 & $\begin{array}{l}\text { Physical, social and health } \\
\text { dimensions improved } \\
\text { especially those with an } \\
\text { EDSS }<3.0\end{array}$ \\
\hline Parkin et al. ${ }^{94}$ & Interferon $\beta 1 \mathrm{~b}$ & $\mathrm{RR}$ & 102 & 12 months & $\begin{array}{l}\text { MSQoL-54, } \\
\text { EQ-5D }\end{array}$ & $\begin{array}{l}\text { Interferon } \beta \text { 1b produces } \\
\text { important occasional short } \\
\text { term QoL gains, but small } \\
\text { gains in quality-adjusted life } \\
\text { years and large additional } \\
\text { costs }\end{array}$ \\
\hline Arnoldus et al. ${ }^{38}$ & Interferon $\beta$ & $\mathrm{RR}$ & 51 & 6 months & $\mathrm{SF}-36$ & $\begin{array}{l}\text { Physical dimensions } \\
\text { improved. More pain within } \\
\text { the first month of treatment }\end{array}$ \\
\hline Freeman et al. ${ }^{39}$ & Interferon $\beta 1 \mathrm{~b}$ & $\mathrm{SP}$ & 718 & 36 months & SIP & $\begin{array}{l}\text { Physical dimension } \\
\text { improved }\end{array}$ \\
\hline Bethoux et al. ${ }^{32}$ & Methylprednisolone & $\mathrm{RR}$ & 24 & 3 months & SF-36 & $\begin{array}{l}\text { Trends for improvement of } \\
\text { physical and mental } \\
\text { composites }\end{array}$ \\
\hline Mathiowetz et al. ${ }^{95}$ & Energy conservation course & RR & 54 & 19 weeks & $\mathrm{SF}-36$ & HRQoL improved \\
\hline Cohen et al. ${ }^{96}$ & $\begin{array}{l}\text { Intramuscular } \\
\text { interferon } \beta 1 \mathrm{a}\end{array}$ & $\mathrm{SP}$ & 436 & 24 months & MSQLI & $\begin{array}{l}\text { Benefit on eight of } 11 \\
\text { MSQLI subscales }\end{array}$ \\
\hline Patti et al..$^{97}$ & $\begin{array}{l}\text { Outpatient rehabilitation } \\
\text { programme }\end{array}$ & $\mathrm{PP} / \mathrm{SP}$ & 58 & 6 weeks & SF-36 & All domains improved \\
\hline Vermersch et al. ${ }^{40}$ & $\begin{array}{l}\text { Intramuscular interferon } \beta \\
\text { la }\end{array}$ & $\mathrm{RR}$ & 121 & 12 months & SF-36 & $\begin{array}{l}\text { No negative effect on MS } \\
\text { patient's HRQoL. }\end{array}$ \\
\hline
\end{tabular}

EQ-5D: European Quality of Life Scale (EuroQoL-5D); LLQ: Laman \& Lankhorst Questionnaire; RR: Remitting-Relapsing; SP: Secondary Progressive; PP: Primary Progressive; SF-36: 36-Item Short-Form Health Survey; QLI: Ferrans and Powers Quality of Life Index; SIP: Sickness Impact Profile; MSQLI: Multiple Sclerosis Quality of Life Inventory; MSQoL-54: Multiple Sclerosis Quality of Life 54; NHP: Nottingham Health Profile; NS: Non-stated. 
permit identification of those aspects of disease most closely linked with patient-rated distress and thus inform targeted treatment.

\section{Relationship between neurological impairment and disability and HRQOL}

A substantial body of evidence demonstrates that HRQoL in MS is associated with impairment and disability as measured by neurological symptoms, the EDSS or the Multiple Sclerosis Functional Composite. ${ }^{98-106}$ However, the strength of the correlation varies enormously depending on the methodology of each individual study. In a Canadian study involving $198 \mathrm{MS}$ patients, QoL scores for all eight scales of the SF-36 were substantially reduced early in the disease. ${ }^{107} \mathrm{In}$ another study involving 98 patients with MS, measures of bodily function, but not EDSS per se was correlated with QoL scores on the SF-36. ${ }^{108}$ It is possible to conclude that neurological impairment and disability only contribute a modest proportion to overall HRQoL. However, this association is not negated when other important variables such as fatigue, cognitive impairment, anxiety and depression are accounted for. ${ }^{101}$ Thus disability appears to have an independent, if modest, contribution to overall HRQoL and over time other variables such as copying style, neuropsychiatric complications and support probably become more significant. $^{21,101}$

Given the widespread use of neuroimaging as a marker of disease severity, it should be no surprise that some groups have reported a similar modest link with HRQoL. For example, in a recent magnetic resonance imaging (MRI) study, brain lesions and atrophy were associated with impaired several domains of HRQoL including sexual dysfunction, poor mental health, and functional limitations. These correlations were stronger for hypointense lesions and atrophy on T1-weighted images than for hyperintense lesions on T2-weighted images. ${ }^{98}$ What is not yet known, is whether neuroimaging can explain a significant proportion of HRQoL over and above that explained by a clinically based patient evaluation.

\section{Relationship between disease course and subtype and HRQoL}

There is some debate regarding the influence of the physical symptoms of MS on HRQoL. While, those living a longer time with MS are likely to have increased levels of disability, poor psychological adjustment to MS is not necessarily related to a longer disease dura- tion or high disease severity. ${ }^{109-111}$ Nevertheless, disease course may influence HRQoL. Specifically, the more aggressive the disease course, the lower the HRQoL. Thus, all other factors being equal, a primary progressive subtype has more negative impact than a secondary progressive subtype which in turn has more negative impact than a relapsing-remitting subtype. ${ }^{30,70}$ It must also be recognised that all subtypes have a haphazard element which is difficult for patients to cope with.

\section{Relationship between cognitive impairment and HRQoL}

The prevalence of cognitive impairment in MS is estimated at $45-65 \%$ and is a feature of all disease subtypes, including groups of patients with normal appearing white matter. ${ }^{12}$ Varying degrees of mild cognitive impairment are much more common than frank dementia. Patients with cognitive impairment are less likely to be professionally and socially active and are more dependent on caregivers than cognitively intact MS patients. ${ }^{113}$ The majority of studies clearly show an association between cognitive impairment and global HRQoL. For example, executive dysfunction and memory impairment are related to a worsening of HRQoL (in particular the physical functioning and mental health subscales of SF-36). ${ }^{114}$ In line with these results, in a recent study involving 209 MS patients our group found that the worse cognitive functioning the lower HRQoL. ${ }^{70}$ However one notable exception found an inverse relationship between HRQoL and cognitive function. Severely affected MS patients with autobiographical impaired memory reported significantly better HRQoL. ${ }^{115}$ One explanation may be the interplay with insight. Patients with significantly impaired cognition tend to have reduced insight into their condition. In this study, patients with normal autobiographical memory reported the highest levels of depression and the lowest levels of HRQoL. Thus it may be that the negative aspects of impaired cognition on HRQoL were offset by poor insight and the advantages of good cognition on HRQoL were confounded by low mood.

\section{Relationship between depression and HRQoL}

Mood disorders, particularly depression and anxiety are very common in MS patients but frequently overlooked. ${ }^{116}$ Depression shows one of the strongest links with lower HRQoL scores in several studies, independent of the clinical course or disability status of MS patients. ${ }^{70,}{ }^{116-122}$ MS depressed patients scored worse in the energy, mental health, cognitive function, overall 
QoL, sexual and emotional function dimensions than non-depressed MS patients. ${ }^{120}$ In a recent paper, a strong inverse correlation was found between the physical and mental dimensions and the depressive symptoms was found using the MSQOL-54 and the Hamilton Depression Rating Scale. ${ }^{12}$ Furthermore, a highly significant correlation between depressive symptoms using the Zung Depression Scale, as well as anxiety using the Zung Anxiety Scale, and the self-assessed quality of life measured with a generic instrument (QoL index). ${ }^{122}$ The negative impact of depression on HRQoL has also been demonstrated by our group. ${ }^{70}$ Bakshi et al. ${ }^{119}$ found that depression was significantly associated with lower HRQoL scores concerning health perception, sexual dysfunction, health distress, mental health, overall QoL, emotional dysfunction, and limitations due to emotional problems. In this study, associations remained significant after adjusting for confounders such as severity of neurologic disability and fatigue. However, there is a conceptual problem in understanding the link between mood and HRQoL. Most scales of HRQoL include ratings of mood, satisfactions and somatic items which are also symptoms of depression. Fundamentally, patients who are currently depressed will give a greater negative evaluation of their wellbeing than those who are not depressed, whether or not a physical illness is also present. Thus it is unavoidable that there will be some overlap between ratings of low mood and HRQoL. However, the association may still prove clinically useful if the depression provides a contribution to HRQoL beyond that explained by other variables or conversely if measures of HRQoL allow greater recognition of depression.

\section{Relationship between fatigue and HRQoL}

The subjective experience of fatigue is one of the most common and disabling symptoms in MS patients. Fatigue is certainly linked with reduced HRQoL, however, the precise way in which fatigue impacts on HRQoL has not been clearly defined. In a recent study involving patients with MS, fatigue as well as depression were independently associated with impaired HRQoL. ${ }^{123}$ Recently, these findings have been corroborated by our group. ${ }^{124}$ Accumulating work suggests that the recognition and treatment of fatigue can improve HRQoL. ${ }^{103}$ The overlap of fatigue and depression may be a methodological concern in the assessment of either. However, in a longitudinal assessment of a cohort of 98 MS patients, depression did not predict the later mental fatigue nor was depression predicted by preceding fatigue experiences. ${ }^{125}$

\section{Conclusions}

Several factors conspire to make MS a disease with major psychological and social ramifications for both patients and their caregivers. These include the onset of MS during the most productive years of life, the uncertain and unstable natural history of the condition, the diffuse effects on the CNS, especially on higher functions, the relative preservation of insight and the absence of convincing disease-modifying treatment. Historically, the assessment of MS has encompassed measures that assess impairment and disability but has omitted important components of HRQoL as volunteered by sufferers themselves. In the last few years, a greater understanding of HRQoL in MS has facilitated several clinical advances. Generic and specific HRQoL instruments have been developed and validated in order to more accurately determine the global impact of MS on an individual and along with the relevant predictive factors. Clinical trials of new pharmacological and non-pharmacological treatments have begun to incorporate HRQoL measures as primary or secondary outcome points. There is now considerable interest in understanding the predictors of HRQoL. Perhaps surprisingly, established physician rated measures of impairment and disability are not as closely linked with HRQoL as patient ratings of handicap and mood. Of particular note, depression has one of the strongest associations with low HRQoL and also influences engagement in rehabilitation and level of distress in caregivers. These findings have been replicated in other neurological diseases. ${ }^{126-128}$ Greater awareness of such influences upon HRQoL is likely to lead to better recognition and treatment of previously overlooked neuropsychiatric complications. Yet the overlap between neuropsychiatric syndromes and HRQoL in its current form, remains a difficult conceptual area. For example, cognitive deficits are a manifestation of MS and a predictor of poor HRQoL but such complaints, when severe, may interfere with self-evaluation. Similarly low mood is a common complication of MS and logically linked with low HRQoL, but depression is likely to disproportionately affect global self-evaluation and hence influence different domains of HRQoL. A simple solution is to allow any complaint, or limitation into a global rating of HRQoL, accepting that each complication adds to the burden of disease as a whole. A more challenging solution is to ask how much does the complication uniquely interfere with that individual's premorbid expectation of their ability to act, think and feel. For example, one might equally ask to what extent does low mood interfere with a patient's ability to enjoy 
seeing friends, as to what extent does the ataxia interfere with the ability to leave the house, unaided. In this sense the impact of a disease will always be more than the total collection of symptoms using any method of measurement. What is more, only the sufferers themselves can attempt to estimate the past, present and anticipated future losses that are causing distress.

We have seen a proliferation of generic and specific HRQoL scales for MS over the last 10 years. It is now time to examine their properties carefully in order to find the scales most suitable for specific situations. It is unlikely that one scale will satisfy all requirements. Most notably clinicians need a concise scale, that can be administered by members of a multidisciplinary team and junior medical staff. Researchers generally need a more comprehensive scale that is particularly sensitive to change. Future developments in this field will include a better delineation of the modifying variables in HRQoL. These may include the impact of doctor-patient communication, availability of local resources, the effect of selfhelp and education strategies, the influence of support and the effects of individual differences in coping and adjustment to illness. HRQoL is now established as an important outcome variable in therapeutic trials in MS where it often highlights areas of most concern to patients and care-givers. The concept of HRQoL is equally important in clinical practice as it emphasizes the importance of neuropsychiatric and social complications as well as the traditional impairment and disability domains that form part of the total burden experienced by patients with MS.

\section{References}

1 Stenager E, Stenager EN, Knudsen L, Jensen K. Multiple sclerosis: the impact on family and social life. Acta Psychiatrica Belgica 1994; 94: $165-174$

(2) 2 Rivera-Navarro J, Morales JM, Benito-León J. Informal caregiving in multiple sclerosis patients: Data from the demyelinating diseases study group from Madrid. Disability and Rehabilitation; (in press).

3 Lynch SG, Kroencke DC, Denney DR. The relationship between disability and depression in multiple sclerosis: the role of uncertainty, coping, and hope. Multiple Sclerosis 2001; 7: 411-416.

4 Patrick DL, Bergner M. Measurement of health status in the 1990s. Annual Review of Public Health 1990; 11: 165-183.

5 Egli $\mathrm{H}$. What constitutes quality of life? Methodological considerations and suggestions for clinical practice. Scandinavian Journal of Gastroenterology 1987; 22(Suppl): S87-S9.

6 Carr AJ, Gibson B, Robinson PG. Measuring quality of life: Is quality of life determined by expectations or experience? $B M J$ 2001; 322: $1240-1243$.

7 Miller DM. Health-related quality of life. Multiple Sclerosis 2002; 8: $269-270$.

8 Kurtzke JF. On the Evaluation of Disability in Multiple Sclerosis. Neurology 1961; 11: 686-694.
9 Rudick RA, Miller D, Clough JD, Gragg LA, Farmer RG. Quality of life in multiple sclerosis. Comparison with inflammatory bowel disease and rheumatoid arthritis. Archives of Neurology 1992; 49: $1237-1242$.

10 Benito-León J, Martínez-Martín P. Calidad de vida relacionada 2 con la salud en la esclerosis múltiple. Neurología 2003 (in press).

11 Dickersin K, Scherer R, Lefebvre C. Systematic ReviewsIdentifying Relevant Studies For Systematic Reviews. British Medical Journal 1994; 309: 1286-1291.

12 Ratsep T, Kallasmaa T, Pulver A, Gross-Paju K. Personality as a predictor of coping efforts in patients with multiple sclerosis. Multiple Sclerosis 2000; 6: 397-402.

13 McCabe MP, McKern S. Quality of life and multiple sclerosis: Comparison between people with multiple sclerosis and people from the general population. Journal of Clinical Psychology Med Settings 2002; 9: 287-295.

14 Hermann BP, Vickrey B, Hays RD, et al. A comparison of healthrelated quality of life in patients with epilepsy, diabetes and multiple sclerosis. Epilepsy Research 1996; 25: 113-118.

15 Cella DF, Dineen K, Arnason B, et al. Validation of the functional 4 assessment of multiple sclerosis quality of life instrument. Neurology 1996; 47: 129-139.

16 Hernández MA. Esclerosis múltiple y calidad de vida. Revista de Neurologia 1996; 24: 1221 - 1223.

17 Rothwell PM. Quality of life in multiple sclerosis. Journal of Neurology, Neurosurgery and Psychiatry 1998; 65: 433.

18 Hernández MA. Tratamiento de la esclerosis múltiple y calidad de vida. Revista de Neurologia 2000; 30: $1242-1245$

19 Vernay D, Gerbaud L, Clavelou P. Qualité de vie et sclérose en plaques. Revue Neurologique (Paris) 2001; 157: 1139-1142.

20 Kurtzke JF. Rating neurologic impairment in multiple sclerosis: an expanded disability status scale (EDSS). Neurology 1983; 33: $1444-1452$.

21 Hobart J, Freeman JA, Thompson AJ. Kurtzke scales revisited: the application of psychometric methods to clinical intuition. Brain 2000; 123: $1027-1040$.

22 Cutter GR, Baier ML, Rudick RA, et al. Development of a multiple sclerosis functional composite as a clinical trial outcome measure. Brain 1999; 122: 871-882.

23 Rothwell PM, McDowell Z, Wong CK, Dorman PJ. Doctors and patients don't agree: cross sectional study of patients' and doctors' perceptions and assessments of disability in multiple sclerosis. British Medical Journal 1997; 314: 1580-1583.

24 Cheng EM, Hays RD, Myers LW, Ellison GW, Beckstrand M, Vickrey BG. Factors related to agreement between self-reported and conventional Expanded Disability Status Scale (EDSS) scores. Multiple Sclerosis 2001; 7: 405-410.

25 Schwartz L, Kraft GH. The role of spouse responses to disability and family environment in multiple sclerosis. American Journal of Physical Medicine and Rehabilitation 1999; 78: 525-532.

26 Rees J, O'Boyle C, MacDonagh R. Quality of life: impact of chronic illness on the partner. Journal of the Royal Society of Medicine 2001; 94: $563-566$.

27 Thompson AJ. Progress in neurorehabilitation in multiple sclerosis. Current Opinion in Neurology 2002; 15: 267-270.

28 Nortvedt MW, Riise T. The use of quality of life measures in multiple sclerosis research. Multiple Sclerosis 2003; 9: 63-72.

29 Nortvedt MW, Riise T, Myhr KM, Nyland HI. Quality of life in multiple sclerosis: measuring the disease effects more broadly. Neurology 1999; 53: $1098-1103$.

30 Pfennings L, Cohen L, Ader H, et al. Exploring differences between subgroups of multiple sclerosis patients in health-related quality of life. Journal of Neurology 1999; 246: 587-591.

31 Lintern TC, Beaumont JG, Kenealy PM, Murrell RC. Quality of life (QoL) in severely disabled multiple sclerosis patients: comparison of three QoL measures using multidimensional scaling. Quality of Life Research 2001; 10: 371-378. 
32 Bethoux F, Miller DM, Kinkel RP. Recovery following acute exacerbations of multiple sclerosis: from impairment to quality of life. Mult Scler 2001; 7: 137-142.

33 Murphy N, Confavreux C, Haas J, et al. Quality of life in multiple sclerosis in France, Germany, and the United Kingdom. Cost of Multiple Sclerosis Study Group. Journal of Neurology, Neurosurgery and Psychiatry 1998; 65: 460-466.

(3) 34 Freeman J, Langdon DW, Hobart JC, Thompson AJ. Healthrelated quality of life in people with multiple sclerosis undergoing inpatient rehabilitation. Journal of Neurol Rehabil 1996; 10: 185194.

35 Schwartz CE, Coulthard-Morris L, Cole B, Vollmer T. The quality-of-life effects of interferon beta- $1 \mathrm{~b}$ in multiple sclerosis. An extended Q-TWIST analysis. Archives of Neurology 1997; 54: $1475-1480$.

36 Nortvedt MW, Riise T, Myhr KM, Nyland HI, Hanestad BR. Type I interferons and the quality of life of multiple sclerosis patients. Results from a clinical trial on interferon alfa-2a. Multiple Sclerosis 1999; 5: 317-322.

37 Rice GP, Oger J, Duquette P, et al. Treatment with interferon beta$1 \mathrm{~b}$ improves quality of life in multiple sclerosis. Canadian Journal of Neurological Sciences 1999; 26: 276-282.

38 Arnoldus JH, Killestein J, Pfennings LE, Jelles B, Uitdehaag BM, Polman CH. Quality of life during the first 6 months of interferonbeta treatment in patients with MS. Multiple Sclerosis 2000; 6: $338-342$.

439 Freeman JA, Thompson AJ, Fitzpatrick R, et al. Interferon-betalb in the treatment of secondary progressive MS: impact on quality of life. Neurology 2001; 57: $1870-1875$.

40 Vermersch P, de Seze J, Delisse B, Lemaire S, Stojkovic T. Quality of life in multiple sclerosis: influence of interferon-betala (Avonex) treatment. Multiple Sclerosis 2002; 8: $377-381$.

(3) 41 Jenkinson C, Fitspatrick R, Argyle M. The Nottingham Health Profile: An analysis of its sensitivity in differentiating illness groups. Soc Sci Med 1988; 27: 1411-1414.

4 42 Bergner M, Bobbitt RA, Carter WB, et al. The Sickness Impact Profile: development and final revision of a health status measure. Medical Care 1981; 19: 787-805.

43 Schwartz L, Kraft GH. The role of spouse responses to disability and family environment in multiple sclerosis. American Journal of Physical Medicine and Rehabilitation 1999; 78: 525-532.

44 Ware JE, Sherbourne CD. The MOS 36-item short form health survey (SF-36). I. Conceptual framework and item selection. Medical Care 1992; 30: 473-83.

45 Brooks R. EuroQoL: the current state of play. Health Policy 1996; 37: $53-72$.

(3) 46 Murrell RC, Kenealy PM. Assessing quality of life in persons with severe neurological disability associated with multiple sclerosis: the psychometric evaluation of two quality of life measures. British Journal of Health Psychology 1999; 4: 349-362.

47 Sharrack B, Hughes RA, Soudain S, Dunn G. The psychometric properties of clinical rating scales used in multiple sclerosis. Brain 1999; 122: $141-159$.

48 Nortvedt MW, Riise T, Myhr KM, Landtblom AM, Bakke A, Nyland HI. Reduced quality of life among multiple sclerosis patients with sexual disturbance and bladder dysfunction. Multiple Sclerosis 2001; 7: $231-235$.

(3) 49 Somerset M, Campbell R, Sharp D, Peters TJ. What do people with MS want and expect from health-care services? Health Expect 2001; 4: $29-37$.

50 Brunet DG, Hopman WM, Singer MA, Edgar CM, MacKenzie TA. Measurement of health-related quality of life in multiple sclerosis patients. Canadian Journal of Neurological Sciences 1996; 23: $99-103$.

51 Freeman JA, Hobart JC, Langdon DW, Thompson AJ. Clinical appropriateness: a key factor in outcome measure selection: the 36 item short form health survey in multiple sclerosis. Journal of Neurology, Neurosurgery and Psychiatry 2000; 68: 150-156.
52 Pfennings L, Cohen L, Miller D, et al. Using the short form-36 with 4 multiple sclerosis patients in five countries: a cross-cultural 4 comparison. Psychological Reports 1999; 85: 19-31.

53 Pozzilli C, Brunetti M, Amicosante AM, et al. Home based (4) management in multiple sclerosis: results of a randomised 4 controlled trial. Journal of Neurology, Neurosurgery and Psychiatry 2002; 73: $250-255$.

54 Hobart J, Freeman J, Lamping D, Fitzpatrick R, Thompson A. The SF-36 in multiple sclerosis: why basic assumptions must be tested. Journal of Neurology, Neurosurgery and Psychiatry 2001; 71: $363-370$

55 Nortvedt MW, Riise T, Myhr KM, Nyland HI. Performance of the SF-36, SF-12, and RAND-36 summary scales in a multiple sclerosis population. Medical Care 2000; 38: 1022-1028.

56 Vickrey BG, Hays RD, Harooni R, Myers LW, Ellison GW. A health-related quality of life measure for multiple sclerosis. Quality of Life Research 1995; 4: 187-206.

57 Vickrey BG, Hays RD, Genovese BJ, Myers LW, Ellison GW. Comparison of a generic to disease-targeted health-related qualityof-life measures for multiple sclerosis. Journal of Clinical Epidemiology 1997; 50: $557-569$.

58 Solari A, Radice D. Health status of people with multiple sclerosis: a community mail survey. Neurological Sciences 2001; 22: 307 315.

59 Schwartz CE, Brotman S, LaRocca N, Lee H. Patient perception of quality of care provided by specialists and generalists. Multiple Sclerosis 1998; 4: 426-432.

60 Hays RD, Sherbourne CD, Mazel RM. The RAND 36-Item (5) Health Survey 1.0. Health Economics 1993; 2: 217-217.

61 Freeman JA, Hobart JC, Thompson AJ. Does adding MS-specific items to a generic measure (the SF-36) improve measurement? Neurology 2001; 57: $68-74$.

62 Lankhorst GJ, Jelles F, Smits RC, et al. Quality of life in multiple 4 sclerosis: the disability and impact profile (DIP). Journal of Neurology 1996; 243: 469-474.

63 Pfennings LE, van der Ploeg HM, Cohen L, Polman CH. A comparison of responsiveness indices in multiple sclerosis patients. Quality of Life Research 1999; 8: 481-489.

64 Jonsson A, Dock J, Ravnborg MH. Quality of life as a measure of rehabilitation outcome in patients with multiple sclerosis. Acta Neurologica Scandinavica 1996; 93: 229-35.

65 Cohen L, Pouwer F, Pfennings LE, et al. Factor structure of the Disability and Impact Profile in patients with multiple sclerosis. (4) Quality of Life Research 1999; 8: 141-150.

66 Pfennings L, Cohen L, van der Ploeg H, Polman C, Lankhorst G. Reliability of two measures of health-related quality of life in patients with multiple sclerosis. Perceptual and Motor Skills 1998; 87: $111-114$

67 Chang CH, Cella DF, Fernández O, et al. Quality of life in multiple 4 sclerosis patients in Spain. Multiple Sclerosis 2002; 8: 527-531.

68 Modrego PJ, Pina MA, Simon A, Azuara MC. The interrelations between disability and quality of life in patients with multiple sclerosis in the area of Bajo Aragon, Spain: a geographically based survey. Neurorehabil Neural Repair 2001; 15: 69-73.

69 Rivera-Navarro J, Benito-León J, Morales JMG, grupo GEDMA. Hacia la búsqueda de dimensiones más especificas en la medición de la calidad de vida en la esclerosis múltiple. Revista de Neurologia 2001; 32: 705-714.

70 Benito-León J, Morales JM, River-Navarro J. Health-related quality of life and its relationship to cognitive and emotional functioning in multiple sclerosis patients. European Neurology 2002; 9: 497-502.

71 Nicholl CR, Lincoln NB, Francis VM, Stephan TF. Assessing quality of life in people with multiple sclerosis. Disability and Rehabilitation 2001; 23: 597-603. 
Gold SM, Heesen C, Schulz H, et al. Disease specific quality of life instruments in multiple sclerosis: validation of the Hamburg Quality of Life Questionnaire in Multiple Sclerosis (HAQUAMS). Multiple Sclerosis 2001; 7: 119-130.

73 Ford HL, Gerry E, Tennant A, Whalley D, Haigh R, Johnson MH. Developing a disease-specific quality of life measure for people with multiple sclerosis. Clinical Rehabilitation 2001; 15: 247-258.

74 Ford HL, Gerry E, Johnson MH, Tennant A. Health status and quality of life of people with multiple sclerosis. Disability and Rehabilitation 2001; 23: 516-521.

75 Hobart J, Lamping D, Fitzpatrick R, Riazi A, Thompson A. The Multiple Sclerosis Impact Scale (MSIS-29): a new patient-based outcome measure. Brain 2001; 124: 962-973.

76 Riazi A, Hobart JC, Lamping DL, Fitzpatrick R, Thompson AJ. Multiple Sclerosis Impact Scale (MSIS-29): reliability and validity in hospital based samples. Journal of Neurology, Neurosurgery and Psychiatry 2002; 73: $701-704$.

77 Fischer JS, LaRocca NG, Miller DM, Ritvo PG, Andrews H, Paty D. Recent developments in the assessment of quality of life in multiple sclerosis (MS). Multiple Sclerosis 1999; 5: 251-259.

78 Rotstein Z, Barak Y, Noy S, Achiron A. Quality of life in multiple sclerosis: development and validation of the 'RAYS' scale and comparison with the SF-36. International Journal of Quality Health Care 2000; 12: $511-517$.

479 Pfennings LE, Van der Ploeg HM, Cohen L, et al. A health-related quality of life questionnaire for multiple sclerosis patients. Acta Neurologica Scandinavica 1999; 100: 148-155.

(3) 480 Nelson E, Wasson J, Kirk J, Keller A, et al. Assessment of function in routine clinical practice: description of the COOP Chart method and preliminary findings. Journal of Chronic Dis 1987; 40(Suppl 1): $55 \mathrm{~S}-69 \mathrm{~S}$.

(3) 81 Ferrans CE, Powers MJ. Quality of life index: development and psychometric properties. ANS Adv Nurs Sci 1985; 8: 15-24.

82 Stuifbergen AK, Roberts GJ. Health promotion practices of women with multiple sclerosis. Archives of Physical Medicine and Rehabilitation 1997; 78(Suppl 5): S3-S9.

(3) 83 Stuifbergen AK. Cognitive impairment and perception of quality of life among individuals with multiple sclerosis. Rehabilitation Nurs Res 1995; 4: 11-18.

(3) 84 Stuifbergen AK. Health-promoting behaviors and quality of life among individuals with multiple sclerosis. Sch Inq Nurs Pract 1995; 9: $31-50$.

85 Schwartz CE, Vollmer T, Lee H. Reliability and validity of two self-report measures of impairment and disability for MS. North American Research Consortium on Multiple Sclerosis Outcomes Study Group. Neurology 1999; 52: 63-70.

86 Petajan JH, Gappmaier E, White AT, Spencer MK, Mino L, Hicks RW. Impact of aerobic training on fitness and quality of life in multiple sclerosis. Annals of Neurology 1996; 39: 432-41.

87 Jonsson A, Dock J, Ravnborg MH. Quality of life as a measure of rehabilitation outcome in patients with multiple sclerosis. Acta Neurologica Scandinavica 1996; 93: 229-235.

88 Di Fabio RP, Choi T, Soderberg J, Hansen CR. Health-related quality of life for patients with progressive multiple sclerosis: influence of rehabilitation. Physical Therapy 1997; 77: 1704-1716.

89 Sitzia J, Haddrell V, Rice-Oxley M. Evaluation of a nurse-led multidisciplinary neurological rehabilitation programme using the Nottingham Health Profile. Clinical Rehabilitation 1998; 12: $389-$ 394.

90 Gianino JM, York MM, Paice JA, Shott S. Quality of life: effect of reduced spasticity from intrathecal baclofen. Journal of Neuroscience Nursing 1998; 30: 47-54.

(3) 91 Husted C, Pham L, Hekking A, Niederman R. Improving quality of life for people with chronic conditions: the example of t'ai chi and multiple sclerosis. Altern Ther Health Med 1999; 5: 70-74.

92 Solari A, Filippini G, Gasco P, Colla L, Salmaggi A, La Mantia L, Farinotti M, Eoli M, Mendozzi L. Physical rehabilitation has a positive effect on disability in multiple sclerosis patients. Neurology 1999; 52: $57-62$.
93 Freeman JA, Langdon DW, Hobart JC, Thompson AJ. Inpatient rehabilitation in multiple sclerosis: do the benefits carry over into the community? Neurology 1999; 52: $50-56$.

94 Parkin D, Jacoby A, McNamee P, Miller P, Thomas S, Bates D. Treatment of multiple sclerosis with interferon beta: an appraisal of cost-effectiveness and quality of life. Journal of Neurology, Neurosurgery and Psychiatry 2000; 68: 144-149.

95 Mathiowetz V, Matuska KM, Murphy ME. Efficacy of an energy conservation course for persons with multiple sclerosis. Archives of Physical Medicine and Rehabilitation 2001; 82: 449-456.

96 Cohen JA, Cutter GR, Fischer JS, et al. Benefit of interferon beta- 4 la on MSFC progression in secondary progressive MS. Neurolog 2002; 59: 679-687.

97 Patti F, Ciancio MR, Reggio E, et al. The impact of outpatient (4) rehabilitation on quality of life in multiple sclerosis. Journal of Neurology 2002; 249: 1027-1033.

98 Janardhan V, Bakshi R. Quality of life and its relationship to brain lesions and atrophy on magnetic resonance images in 60 patients with multiple sclerosis. Archives of Neurology 2000; 57: 1485-91.

99 Miller DM, Rudick RA, Cutter G, Baier M, Fischer JS. Clinical significance of the multiple sclerosis functional composite: relationship to patient-reported quality of life. Archives of Neurology 2000; 57: $1319-1324$

100 de Andrés C, Guillem A. Una aproximación sobre la calidad de vida en pacientes con esclerosis multiple. Revista de Neurologia 2000; 30: $1229-1234$.

101 Henriksson F, Fredrikson S, Masterman T, Jonsson B. Costs, quality of life and disease severity in multiple sclerosis: a crosssectional study in Sweden. European Journal of Neurology 2001; 8: $27-35$.

102 O'Connor P, Lee L, Ng PT, Narayana P, Wolinsky JS. Determinants of overall quality of life in secondary progressive MS: a longitudinal study. Neurology 2001; 57: 889-891.

103 Janardhan V, Bakshi R. Quality of life in patients with multiple sclerosis: the impact of fatigue and depression. Journal of Neurological Sciences 2002; 205: $51-58$.

104 Koch LC, Rumrill Jr. PD, Roessler RT, Fitzgerald S. Illness and demographic correlates of quality of life among people with multiple sclerosis. Rehabil Psychol 2001; 46: 154-164.

105 Rudick RA, Cutter G, Baier M, et al. Use of the Multiple (4 Sclerosis Functional Composite to predict disability in relapsing MS. Neurology 2001; 56: $1324-1330$.

106 Nortvedt MW, Riise T, Myhr KM, Nyland HI. Quality of life as a predictor for change in disability in MS. Neurology 2000; 55: $51-$ 54.

107 The Canadian Burden of Illness Study Group. Burden of illness of multiple sclerosis: Part II: Quality of life. The Canadian Burden of Illness Study Group. Canadian Journal of Neurological Science 1998; 25: 31-38.

108 Kugler J, Kahrmann G, Gockel M, Pohlau D. Determinants for quality of life and emotional disorder in patients with multiple sclerosis. Psychosomatic Medicine 1999; 61: 111. Abstract.

109 Barnwell AM, Kavanagh DJ. Prediction of psychological adjustment to multiple sclerosis. Social Science and Medicine 1997; 45: $411-418$.

110 Aronson KJ. Quality of life among persons with multiple sclerosis and their caregivers. Neurology 1997; 48: 74-80.

111 Burnfield A, Burnfield P. Psychosocial aspects of multiple sclerosis. Physiotherapy 1982; 68: 149-150.

112 Bagert B, Camplair P, Bourdette D. Cognitive dysfunction in multiple sclerosis: natural history, pathophysiology and management. CNS Drugs 2002; 16: 445-455.

113 Rao SM, Leo GJ, Ellington L, Nauertz T, Bernardin L, Unverzagt F. Cognitive dysfunction in multiple sclerosis. II. Impact on employment and social functioning. Neurology 1991; 41: $692-696$.

114 Cutajar R, Ferriani E, Scandellari C, et al. Cognitive function and 4 quality of life in multiple sclerosis patients. Journal of Neurovirology 2000; 6(Suppl): S186-S190. 
115 Kenealy PM, Beaumont GJ, Lintern T, Murrell R. Autobiographical memory, depression and quality of life in multiple sclerosis. Journal of Clinical Experimental Neuropsychology 2000; 22: 125131.

116 Minden SL, Orav J, Reich P. Depression in multiple sclerosis. General Hospital Psychiatry 1987; 9: 426-434.

117 Provinciali L, Ceravolo MG, Bartolini M, Logullo F, Danni M. A multidimensional assessment of multiple sclerosis: relationships between disability domains. Acta Neurologica Scandinavica 1999; 100: $156-162$.

(4) 118 Solari A, Filippini G, Mendozzi L, et al. Validation of Italian multiple sclerosis quality of life 54 questionnaire. Journal of Neurology, Neurosurgery and Psychiatry 1999; 67: 158-162.

(4) 119 Bakshi R, Shaikh ZA, Miletich RS, et al. Fatigue in multiple sclerosis and its relationship to depression and neurologic disability. Multiple Sclerosis 2000; 6: 181-185.

120 Wang JL, Reimer MA, Metz LM, Patten SB. Major depression and quality of life in individuals with multiple sclerosis. International Journal of Psychiatry in Medicine 2000; 30: 309-317.

121 Amato MP, Ponziani G, Rossi F, Liedl CL, Stefanile C, Rossi L. Quality of life in multiple sclerosis: the impact of depression, fatigue and disability. Multiple Sclerosis 2001; 7: 340-344.

122 Fruehwald S, Loeffler-Stastka H, Eher R, Saletu B, Baumhackl U. Depression and quality of life in multiple sclerosis. Acta Neurologica Scandinavica 2001; 104: 257-261.
123 Merkelbach S, Sittinger H, Koenig J. Is there a differential impact of fatigue and physical disability on quality of life in multiple sclerosis? Journal of Nervous and Mental Disease 2002; 190: 388 393.

124 Morales JM, Benito-León J, Rivera-Navarro J, Otero B. Relación de la fatiga con la calidad de vida relacionada con la salud y el estado emocional en la esclerosis múltiple. Neurología 2002; 17: 572. Abstract.

125 Schreurs KM, de Ridder DT, Bensing JM. Fatigue in multiple sclerosis: reciprocal relationships with physical disabilities and depression. Journal of Psychosomatic Research 2002; 53: 775-781.

126 Schrag A, Jahanshahi M, Quinn N. What contributes to quality of life in 34 patients with Parkinson's disease? Journal of Neurology, Neurosurgery and Psychiatry 2000; 69: 308-312.

127 Lou RS, Reeves A, Benice T, Sexton G. Fatigue and depression are associated with poor quality of life in ALS. Neurology 2003; 60: $122-123$.

128 Kauhanen ML, Korpelainen JT, Hiltunen P, Nieminen P, Sotaniemi KA, Myllyla VV. Domains and determinants of quality of life after stroke caused by brain infarction. Archives of Physical Medicine and Rehabilitation 2000; 81: 1541-1546.

129 Knight RG, Devereux RC, Godfrey HPD. Psychosocial consequences of caring for a spouse with multiple sclerosis. Journal of Clinical and Experimental Neuropsychology 1997; 19: 7-19. 


\section{TIDS}

\begin{tabular}{|l|l|}
\hline Manuscript No. & 101011 \\
\hline Author & \\
\hline Editor & \\
\hline Master & \\
\hline Publisher & \\
\hline
\end{tabular}

Disability \& Rehabilitation Typeset by Elite Typesetting for

Taylor \&Francis

healthsciences

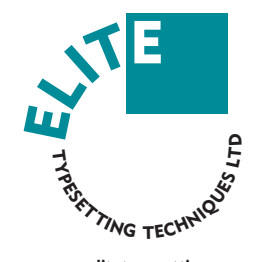

www.elitetypesetting.com

\section{QUERIES: \\ to be answered by AUTHOR}

AUTHOR: The following queries have arisen during the editing of your manuscript. Please answer the queries by marking the requisite corrections at the appropriate positions in the text.

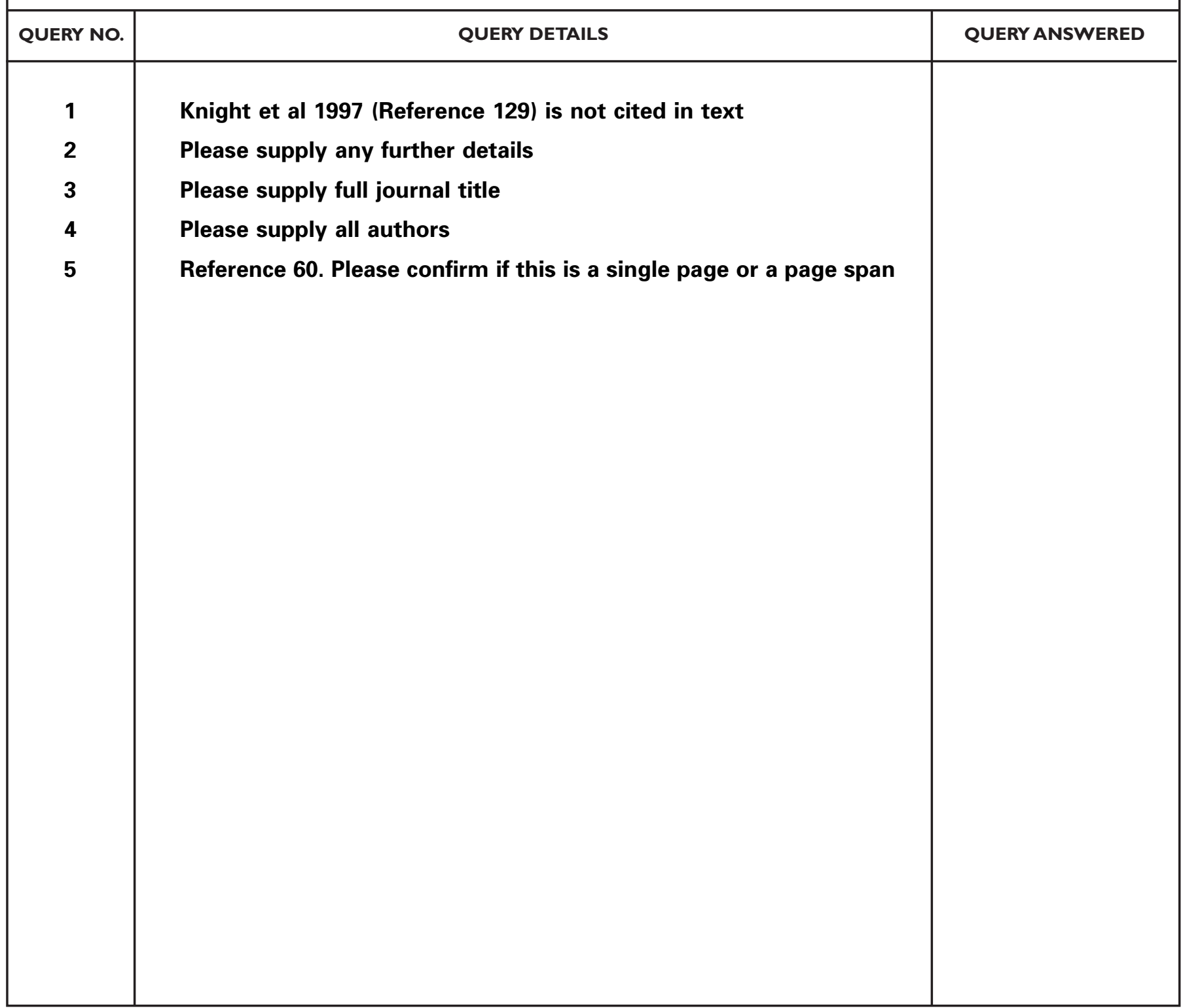

